\title{
The Exploration of Mathematical Intuition and Its Role in Solving Mathematical Problem
}

\author{
Arwanto \\ Post-graduate Student (S3) of Mathematic Education, \\ Universitas Negeri Surabaya \\ adearwan49@gmail.com
}

\author{
I Ketut Budayasa, Mega Teguh Budiarto \\ Department of Mathematics, FMIPA Universitas Indonesia, \\ Kampus UI Depok, Depok 16242, Indonesia \\ iketutbudayasa@yahoo.co.id, megatbudiona@yahoo.co.id
}

\begin{abstract}
This type of research is qualitative since it aims at finding out the exploration of mathematical intuition and its role in solving mathematical problems. The research method was done by collecting data through mathematical problem-solving test according to Polya stages and conducting in-depth interview with the subject afterwards. The subject of the study consists of female students of mathematics education program of the Muhammadiyah University of Cirebon. There were 50 people and one female student was taken to be involved in this study. The result of the research shows that the mathematical exploration of intuition and its role in solving mathematical problems including: (1). When the subject was given a problem in solving mathematical problems, an exploration of intuition and the role arises. When the subject made a mathematical problemsolving plan using intuition exploration the role appeared was direct. the subject did not use exploration intuition in making plans and implementing mathematical problem solving, the subject tended to use the intuition exploration in re-examining the answer. (2). When the subject was given the second question; in understanding mathematical problems not using exploratory intuition, making plans and implementing solving mathematical problem, and re-examining problem solving; the subject used affirmatory intuitive exploration. In this research, exploration and the role of intuition occurred in accordance with the stages of solving mathematical problems starting from understanding the problem, making plans and carrying out problem solving, as well as re-examining mathematical problem solving, in which the subject often experience changes in her intuition exploration.
\end{abstract}

Keywords — Intuition, Mathematical Problem Solving.

\section{INTRODUCTION}

Mathematicians have traditionally used intuition to understand evidence and conceptualize problems [1]. The following outlines the role of intuition in mathematical activity. The analytic and logical thinking process play an important role in representing the structure of mathematical knowledge. It shows that mathematical thinking is produced through the conscious mental process, and is based on mathematical logic and mathematical proof. The conscious mental process is a mental process that can be controlled deliberately. The process of formulating mathematical knowledge through the association between notation and symbol with mathematical ideas requires mental activity called cognition immediately (formal cognition). Formal cognition is a cognition that is controlled by mathematical logic and mathematical evidence either through mathematical induction or by deduction [2]. However, formal cognition does not explain every step in the mathematical activity. Jung psychologist states that intuition is one of the cognitive functions among three other functions, namely: thinking, feeling, and sensation [3].

Bunge [4] states that intuition is a reason, which has characteristics: catalytic inference, power of synthesis and common sense. The catalytic inference is a shortcut from a proposition to another proposition, that is, by jumping to the conclusion precisely without considering the premise and intermediary. Power of synthesis is the ability to combine the heterogeneity or dispersed elements into an overall unity or harmony. Meanwhile, common sense is a consideration that is sustained by general knowledge (ordinary knowledge).

Westcott [4] stated that the conclusions based on intuition are typically characterized by explicit information that is slightly / less than the information generally required to achieve a conclusion. (An institution-based conclusion is typically characterized by less explicit information than the ordinary, which is required to reach that conclusion). For example, one says "one and two" go on to say "three and how much?" Someone else who listens may say "four" or maybe the other says "six". Westcott, however, states that the subject actually uses explicit information that is available and needed before attempting to complete an accurate one. According to Westcott, successful intuitive thinkers tend to have high mathematical intelligence as well as the others.

Wild [3] says that the definition of intuition commonly used by such experts is an idea to achieve a conclusion, a process of synthesis, a process of formulating, or problemsolving without awareness of the process so that conclusion or synthesis is achieved. In this case, [2] suggests that in analyzing students' mathematical behavior, there are three aspects to be taken into account: formal aspects (definitions, theorems and so on), algorithmic aspects (breaking techniques and standard strategies), and intuitive aspects against concepts, theorems, or mathematical solutions). 


\section{METHOD}

The method used in this study were tests, interviews, and documentation since, for qualitative researchers, the phenomenon could only be understood meaningfully if an interaction was done with the subject through the provision of tests which was then continued by in-depth interviews. In addition, to complete the data, documentation (about materials written about the subject) was needed. The tests for questions 1 and 2 were done for the data collection techniques about exploration issues and their role in solving mathematical problems. Giving interviews with the intention of digging indepth data was the next data collection technique. The interview was task-based semi-structured interview meaning that researchers asked several in-depth questions related to the focus of the problem so that the data needed in the research could be collected optimally. Meanwhile, documentation was used to collect data from non-human sources. It consisted of documents and records used as a written material or statement prepared by researchers with the aim of proving the existence of an event or being a consideration. Documentation is usually used to prepare things for specific purposes, which can be in the form of letters, diaries, special notes, photographs and so on

\section{RESULT AND DISCUSSION}

The results and discussion focus on the problems given to the female student of mathematics education dealing with the exploration of the intuition and the role of it in solving mathematical problems according to the stages of Polya. The following is the problem given:

A HEXOS candy company has three sales stores in Cirebon City. Each store provides 100 boxes of candies. One box consists of 15 large packs. Each large package containing 12 small packs of candies. The price of a small pack of candies is Rp. 7.500, -

The HEXOS candy company incurs expenses from each store for the following purposes
a. $25 \%$ to pay employee salary
b. $20 \%$ to capital and raw materials
c. $10 \%$ to store operating costs
Questions:

1). If all the HEXOS candies are sold out, what is the sales from 1 store?

2). What is the net profit of HEXOS candy company from the 3 stores?
a. $25 \%$ to pay employee salaries
b. $20 \%$ to capital and raw materials
c. $10 \%$ to store operating costs

TABLE I. LIST OF THE TYPES OF INTUITION EXPLORATION AND ITS ROLE THAT CAN BE OBSERVED IN RESEARCH

\begin{tabular}{|c|c|c|}
\hline No & Polya Steps & $\begin{array}{c}\text { Type of institution exploration and its } \\
\text { role }\end{array}$ \\
\hline 1. & $\begin{array}{l}\text { Understanding the } \\
\text { Problem }\end{array}$ & $\begin{array}{l}\text { The subject, the female students, used the } \\
\text { role and exploration of mathematical } \\
\text { intuition at the stage of understanding } \\
\text { mathematical problems. It was proved by } \\
\text { the results of the stage in which the subject } \\
\text { understood the mathematical problem } \\
\text { received directly from a fact or information } \\
\text { given in the form of a text question } \\
\text { mathematical problem. Therefore, the } \\
\text { intuition used by the subject in } \\
\text { understanding the subject matter belongs to } \\
\text { direct affirmation intuition which was } \\
\text { directly understood from the material of the } \\
\text { mathematical problem. }\end{array}$ \\
\hline 2. & $\begin{array}{l}\text { Creating a } \\
\text { troubleshooting plan }\end{array}$ & $\begin{array}{l}\text { The subject used the role and exploration of } \\
\text { global anticipatory intuition at the stage of } \\
\text { making problem-solving plans. It was } \\
\text { proven by the way the subject gave reasons } \\
\text { dealing with the emergence of the intuition } \\
\text { after she tried to make plans in order to } \\
\text { solve mathematical problems. It was done } \\
\text { by looking at the text information about the } \\
\text { formula to be used. Furthermore, the } \\
\text { formula only appeared from the information } \\
\text { taken when viewing problem text that the } \\
\text { subject could not explain in detail. }\end{array}$ \\
\hline 3. & $\begin{array}{l}\text { Implementing } \\
\text { problem-solving plan }\end{array}$ & $\begin{array}{l}\text { The subject used the role and exploration of } \\
\text { formal cognition at the stage of } \\
\text { implementing a mathematical problem- } \\
\text { solving plan. It was proved through the way } \\
\text { the subject directly worked using number } \\
\text { operating formulas. In addition, the subject } \\
\text { did not encounter problems in implementing } \\
\text { mathematical problem-solving plans. That } \\
\text { was why there was no alternative ideas } \\
\text { emerged. Therefore, it could be said that the } \\
\text { subject implemented a mathematical } \\
\text { completion plan without using roles and } \\
\text { exploring mathematical intuition in this } \\
\text { stage. }\end{array}$ \\
\hline 4. & Doing Checking & $\begin{array}{l}\text { The subject, at the stage of re-examining } \\
\text { mathematical answers, examined and } \\
\text { repeated the answers gradually and } \\
\text { thoroughly by checking the answers using } \\
\text { their thoughts according to what they have } \\
\text { planned. Thus, it could be said that the } \\
\text { subject used formal cognition. In addition, } \\
\text { the did not use other methods, which might } \\
\text { be a kind of direct cognition. Thus, it could } \\
\text { be said that the subject, at the stage of } \\
\text { checking answers, did not use the role and } \\
\text { exploration of mathematical intuition. }\end{array}$ \\
\hline
\end{tabular}

\section{CONCLUSION}

Based on data analysis and discussion, it can be drawn conclusion as follows: The result of the research shows the exploration of student intuition and its role in solving the mathematical problems. At the stage of understanding mathematical problems, the subject used roles and exploration of mathematical intuition, proved by the results of the stages done by the subject to understand mathematical problems received directly from a fact or information given in the form of a mathematical problem in text question. Thus, the intuition 
used by the subject in understanding the subject matter belonged to direct affirmation intuition type, which was directly gotten from the material of mathematical problems. At the stage of making a mathematical completion plan, the subject used the role and exploration of global anticipatory intuition. It was proven by the way the subject gave reasons dealing with the emergence of the intuition after she tried to make plans in order to solve mathematical problems. It was done by looking at the text information about the formula to be used. Furthermore, the formula only appeared from the information taken when viewing problem text that the subject could not explain in detail. The subject used the role and exploration of formal cognition at the stage of implementing a mathematical problem-solving plan. It was proved through the way the subject directly worked using number operating formulas. In addition, the subject did not encounter problems in implementing mathematical problem-solving plans. That was why there was no alternative ideas emerged. Therefore, it could be said that the subject implemented a mathematical completion plan without using roles and exploring mathematical intuition in this stage. At the stage of reviewing the math answers, the subject checked and repeated the answers done in stages thoroughly. The answers checking was done through the way the subject used mind according to what had been planned. Thus, it could be said that the subject uses formal cognition. In addition, the subject did not use other methods such as direct cognition. Thus, it could be said that the subject, at the answer checking stage, did not use the role and exploration of mathematical intuition.

\section{REFERENCES}

[1] D. F. Halpern, Sex Differences in Cognitive abilities, Hillsdale, N.J. Lawrence Erlbaum Association, 1986.

[2] E. Fischbein, "The interaction between the Formal, the Algorithmic, and the intuitive Components in a Mathematical Activity", Didactics of Mathematics as a Scientific Discipline, pp.231-245, 1994.

[3] G. Henden, Intuition and Its Role in Strategic Thinking, Norwegian: Disertasion unpublished, 2004.

[4] D. Santos, S. Ursini, M. P. Ramirez, and G. Sanchez, "Mathematics achievement: sex differences vs gender differences", Proceeding $30^{\text {th }}$ Conference of the International Group for the Psicology of Mathematics Education, vol. 5, pp. 41-48, 2006. 